\title{
A INFLUÊNCIA DE ÁREAS VERDES NO COMPORTAMENTO HIGROTÉRMICO E NA PERCEPÇÃO AMBIENTAL DO CITADINO EM DUAS UNIDADES AMOSTRAIS NO MUNICÍPIO DE PORTO VELHO, RONDÔNIA, BRASIL
}

\author{
Graziela Tosini Tejas"; Marília Gabriela F. de Azevedo ${ }^{2}$; Marília Locatelli ${ }^{3}$
}

(recebido em 03.06.2011 e aceito para publicação em 15.12.2011)

\section{RESUMO}

O presente trabalho analisou a influência de áreas verdes no comportamento higrotérmico e na percepção ambiental em duas unidades amostrais, levando-se em consideração a presença e ausência de vegetação arbórea, na cidade de Porto Velho, Rondônia, Amazônia Meridional, Brasil. A análise foi realizada a partir de uma investigação experimental onde os dados, de temperatura e umidade relativa do ar, foram mensurados através de termohigrômetros, nos horários estabelecidos pela Organização Mundial Meteorológica (OMM). Os dados de percepção ambiental foram obtidos através de questionários semi-estruturados no momento do monitoramento climático. Os resultados demonstraram que na área arborizada os valores higrotérmicos foram inferiores ao ponto em que há ausência de vegetação (área construída) alcançando uma diferença de $3^{\circ} \mathrm{C}$ a $5^{\circ} \mathrm{C}$. Quanto à avaliação da percepção ambiental verificou-se que os entrevistados sentem-se mais confortável (73\%) no ponto com presença de vegetação e apontaram que a arborização na urbe propicia (57\%) a redução do calor.

Palavras-chave: Cobertura arbórea urbana; Conforto climático; Qualidade ambiental.

\footnotetext{
1. Mestranda em Geografia pelo Programa de Pós-Graduação da Fundação Universidade Federal de Rondônia; Pesquisadora e Colaboradora do Laboratório de Geografia e Planejamento Ambiental; Bolsista CAPES. grazitosini@gmail.com

2. Bióloga; Especialista em Gestão Ambiental pela Faculdade São Lucas, Porto Velho-RO. gabiazevedo19@hotmail.com

3. Engenheira Florestal; MSc em Ciência Florestal; PhD em Ciência do Solo; Pesquisadora Embrapa Rondônia; Professora do Mestrado em Geografia da Fundação Universidade Federal de Rondônia, campus Porto Velho,RO. marilia@cpafro.embrapa.br
} 


\title{
THE GREEN AREAS INFLUENCE IN HYGROTERMAL BEHAVIOR AND CITADINE ENVIRONMENTAL PERCEPTION IN TWO SAMPLE UNITS IN THE CITY OF PORTO VELHO, RONDÔNIA, BRAZIL
}

\begin{abstract}
This study examined the influence of green areas in the hygrothermal behavior and environmental perception in two sampling units, taking into account the presence and absence of woody vegetation in the city of Porto Velho, Rondônia, southern Amazon, Brazil. The analysis was performed from an experimental investigation where temperature and relative humidity data were measured using thermo-hygrometers, at times established by the World Meteorological Organization (WMO). Environmental sensing data were obtained through semi-structured questionnaires at the time of climate monitoring. The results showed that the hygrothermal wooded area values were below the point where there is an absence of vegetation (built area) reaching a difference of $3{ }^{\circ} \mathrm{C}$ to $5{ }^{\circ} \mathrm{C}$. The environmental perception evaluation demonstrated that respondents feel more comfortable $(73 \%)$ in the point with presence of vegetation and pointed out that afforestation in the city provides (57\%) of heat reduction.
\end{abstract}

Keywords: Urban tree canopy; Climatic comfort; Environmental quality.

\section{INTRODUÇÃO}

A cidade é a materialização do processo de urbanização manifestada pela aglomeração de pessoas com suas construções e atividades (MENDONÇA; MONTEIRO, 2003). Segundo Mumford (2004) a cidade surgir como uma emergente na comunidade paleoneolítica, a partir da necessidade de (re) organização das funções e serviços que antes estavam dispersos e agora por estarem reunidas em uma área limitada, possibilitou uma nova organização social e espacial.

Os adensamentos dos centros urbanos propiciaram uma transformação da paisagem (natural para artificial) tendo como consequência, dentre outros fatores, a modificação dos 
aspectos físicos do clima e dos elementos climáticos (NÓBREGA; VITAL, 2010). Santos (2008) explica que os progressos das indústrias química e mecânica, bem como, o da genética e da informática contribuíram não somente para a formação desses adensamentos urbanos, como também tem provocado implicações na qualidade de vida do citadino, uma vez que os homens deixaram de entender a natureza como amiga e a transformaram em um elemento hostil a paisagem urbana. Todavia, contraditoriamente, as primeiras preocupações com a qualidade do ambiente urbano remetem ainda ao período da Revolução Industrial (BRANDÃO, 2003).

Dentre os principais impactos causados pelo crescimento desordenado das áreas urbanas, que a ciência tem se debruçado buscando a compreensão e possíveis soluções, destaca-se o fenômeno das "ilhas de calor". Esse processo é caracterizado pelo incremento da temperatura nas regiões centrais da cidade em relação as suas áreas circunvizinhas. Segundo Bias, Baptista e Lombardo (2003), a ilha de calor se deve principalmente, pelos diferentes tipos de materiais empregados na construção civil, adensamentos urbanos e a diminuição de áreas arborizadas. Lombardo (1985) explica que o resultado da ilha de calor no ambiente urbano é a produção de um stress térmico persistente que muitas vezes ultrapassa os limites tolerados para uma vida saudável.

A introdução de áreas verdes tem-se configurado como um paliativo a formação de ilhas de calor, além de propiciar ambientes mais confortáveis aos habitantes das regiões urbanas. A esse respeito, Gomes e Amorim (2003) afirmam que determinadas espécies utilizadas na arborização urbana reduzem os efeitos da radiação solar e oferecem conforto térmico ao ambiente. Segundo Barbirato et al., (2007, pg.145) "nos centros urbanos as áreas verdes são indispensáveis na prevenção de situações de desconforto, de gastos energéticos com a climatização de edifícios e do efeito urbano de ilha de calor". Além desses benefícios, do ponto de vista psicológico e social a arborização urbana influencia sobre o estado de ânimo dos indivíduos massificados com o transtorno das grandes cidades, ainda proporcionam ambiente agradável para a prática de esportes, exercícios físicos e recreação em geral, Gomes e Soares (2003).

Para avaliar os efeitos da qualidade de vida do citadino desenvolveu-se a técnica da percepção ambiental, no qual abrange o inter-relacionamento entre o comportamento e o ambiente. É um método que associa Psicologia com a Sociologia e a Ecologia auxiliando na compreensão das expectativas, satisfações e insatisfações relacionadas com o conforto e o bem estar social (ARAÚJO et al., 2010). Assim, pressupõe pensar e investigar o conjunto 
(natural e social) e de que maneira este todo se manifesta na realidade, Pereira e Ferreira (2009).

Neste sentido, o presente estudo teve por objetivo analisar a influência das áreas verdes no comportamento higrotérmico e na percepção ambiental em duas unidades amostrais no município de Porto Velho, Rondônia, Brasil.

\section{MATERIAIS E MÉTODOS}

\section{Caracterização da cidade de Porto Velho}

Porto Velho, capital do estado de Rondônia, está situada na Amazônia Meridional

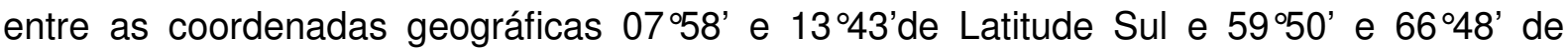
Longitude a Oeste de Greenwich com uma área urbana de 116,90 km² (PORTO VELHO, 2008). O estado de Rondônia está em uma área de transição entre o domínio morfoclimático do cerrado e o Amazônico. O tipo de vegetação predominante é a Floresta Ombrófila Aberta que ocupa maior área ainda vegetada, e esse tipo de floresta caracteriza-se por possui um dossel descontínuo o que favorece a penetração da luz solar propiciando a regeneração, no qual o seu estrato mais alto pode atingir até $30 \mathrm{~m}$ de altura, assim é possível encontrar cipós, palmeiras, bambus e sororocas (SILVA; VINHA, 2002, p.97). A composição florística e o relevo revelam quatro fisionomias, e uma delas é de ocorrência na área de estudo sendo a Floresta Ombrófila Aberta de Terras Baixas disposta em relevo plano a suavemente ondulado não ultrapassando os 100 m de altitude (SILVA; VINHA, 2002, p.97).

Segundo Bastos e Sá Diniz (1982) o clima de Porto Velho de acordo com o sistema de Köppen está submetido ao grupo de clima tropical chuvoso com o tipo Am, com características de elevados índices pluviométricos e um breve período de estiagem (três meses secos). Gama (2002) ao analisar o clima de Rondônia afirmou que o município de Porto Velho está inserido em uma região com duas estações climáticas distintas e bem definidas. O período chuvoso ocorre de outubro a abril e o período seco nos meses de junho, julho e agosto, sendo que os meses de maio e setembro são períodos de transição. Assim, Santos Neto (2010a) explica que a estação chuvosa é denominada de inverno amazônico e a estação seca de verão amazônico, devido ao costume local e por associarem aos períodos secos e chuvosos à sensação térmica. 
Segundo as Normais Climatológicas de 1975-1990 (BRASIL, 1992), obtidas através do Instituto Nacional de Meteorologia (INMET), demonstra que Porto Velho apresenta uma temperatura média anual de $25^{\circ} \mathrm{C}$ com máxima de $31^{\circ} \mathrm{C}$ e mínima de $21^{\circ} \mathrm{C}$. Os meses mais quentes são agosto e setembro $\left(33^{\circ} \mathrm{C}\right)$ e o mês de julho $\left(18^{\circ} \mathrm{C}\right)$ pode atingir a menor temperatura do ar. Para a umidade relativa do ar a média anual é de $85 \%$ com máxima de $89 \%$ em janeiro e mínima no mês de julho (80\%).

\section{Descrição das unidades amostrais}

O estudo foi realizado em duas unidades amostrais urbanas na zona central da cidade de Porto Velho-RO. Localizados no bairro Centro, situados na Avenida Presidente Dutra esquina com a Avenida Carlos Gomes denominado de Ponto 1, e na Rua Tenreiro Aranha esquina com Avenida Carlos Gomes de Ponto 2, no sentido Oeste-Leste da cidade (Figuras 1 e 2). As características das duas unidades amostrais são apresentadas no Quadro 1, no qual houve a prioridade de estabelecer o monitoramento em diferentes arranjos espaciais, compreendendo assim a presença de vegetação arbórea e em outra ausência de vegetação, a fim de analisar o comportamento térmico dessas áreas.

As espécies arbóreas presentes no Ponto 1 são: a) Cássia-imperial (Cassia fistula L.) que apresenta porte médio e crescimento rápido, alcançando cerca de 5 a 10 metros de altura. Possui tronco elegante, um pouco tortuoso, e pode ser simples ou múltiplo, com a casca cinza-esverdeada. A copa é arredondada, com cerca de 4 metros de diâmetro. No verão apresenta suas inflorescências, do tipo racemo, pendentes e longas, com cerca de 30 cm de comprimento e com numerosas flores amarelas, pentâmeras e grandes. Suas raízes não são agressivas, podendo ser plantada em calçadas; b) Oiti (Licania tomentosa), árvore de porte médio a grande ( 8 a $15 \mathrm{~m}$ ), de copa frondosa, crescimento rápido, flores pequenas e brancas, de pétalas curvas, agrupadas em cachos. 
Figura 1. Localização da área de estudo, Porto Velho, Rondônia

Figure 1. Location of study area, Porto Velho Rondônia

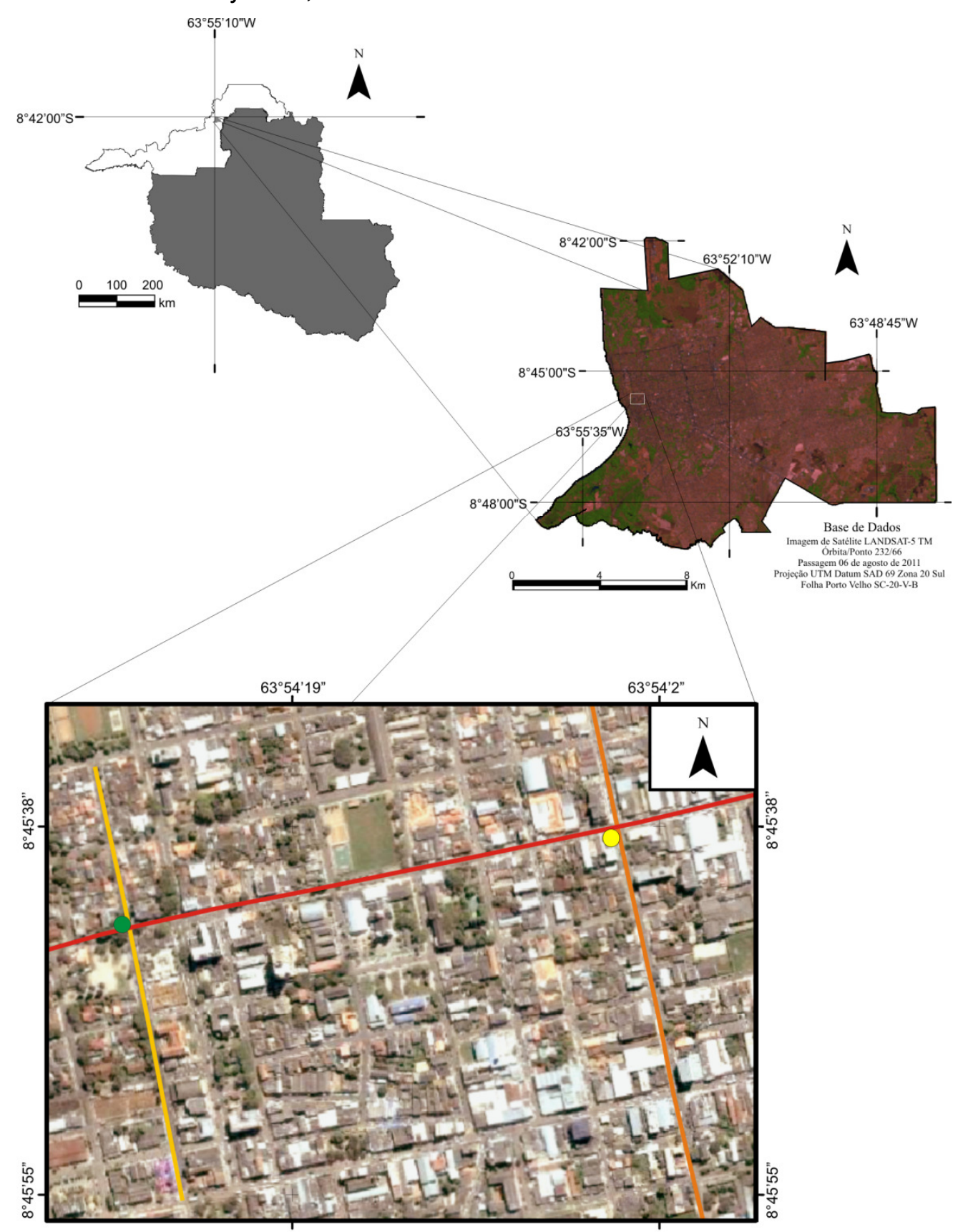

\section{LEGENDA}

Ruas e Avenidas

Av. Presidente Dutra
Rua Tenreiro Aranha

Av. Carlos Gomes

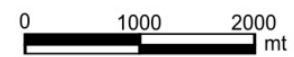

Ponto 1 - Ambiente com presença de vegetação

Ponto 2 - Ambiente com ausência de vegetação

Base de Dado Imagem de Satélite SPOT Passagem 09 de setembro de 2009 Follo $20 \mathrm{~S}$ 
Figura 2. Aspectos das unidades amostrais. ponto 1- com arborização, situado na avenida presidente dutra e ponto 2 - área construída, situada na rua Tenreiro Aranha em Porto Velho, Brasil

Figure 2. Aspects of the sampling units. point 1 - with trees, located on the avenue Presidente Dutra and point 2 - built area, located on the street Tenreiro Aranha in Porto
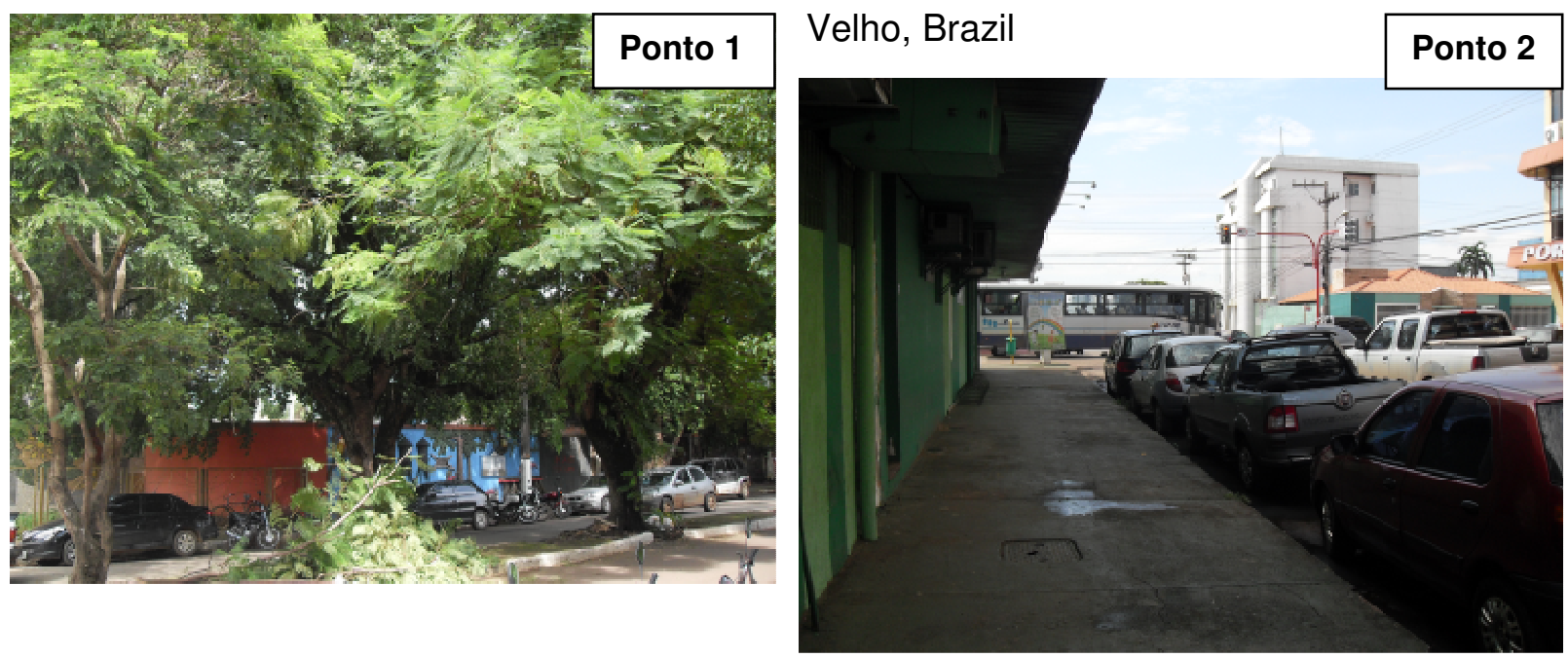

Quadro 1. Síntese das características das duas unidades amostrais urbanas em Porto Velho, RO, Brasil

Box 1. Synthesis of features of the two urban sampling units in Porto Velho, RO, Brazil

\begin{tabular}{|c|c|c|c|c|c|c|}
\hline \multirow{2}{*}{ Ponto } & \multicolumn{3}{|c|}{ Solo } & \multirow{2}{*}{ Tipologia das Edificações } & Tráfego de Veículos & Vegetação \\
\cline { 2 - 6 } & Uso & Ocupação & Cobertura & & Intenso & Presente \\
\hline $\mathbf{1}$ & Misto & Intensa & Asfalto & Térreo e $\leq 2$ pavimentos & Intenso & Ausente \\
\hline $\mathbf{2}$ & Misto & Intensa & Asfalto & $<3$ pavimentos & Tunn \\
\hline
\end{tabular}

\section{Procedimento metodológico}

O controle higrotérmico dos pontos foi realizado nos dias 14,15 e 16 de agosto de 2010 e nos dias 13,14 e 15 de novembro de 2010, nos horários de 08h, 14h e 20h, conforme horários indicados pela Organização Mundial de Meteorologia (OMM), adaptado ao fuso horário local. 
Para os registros de temperatura e umidade relativa do ar foram utilizados Termohigrômetro digitais da marca Instrutherm, modelo HT200, previamente aferidos. O registro de umidade relativa apresenta uma faixa de leitura de $20 \%$ a $99 \%$ com precisão de $\pm 5 \%$. Quanto à temperatura do ar é observada no equipamento uma leitura $\left(-20^{\circ} \mathrm{C}\right.$ a $70^{\circ} \mathrm{C} \mathrm{e}-4 \mathrm{a}$ $\left.158^{\circ} \mathrm{F}\right)$ com precisão de $\pm 1{ }^{\circ} \mathrm{C}$ e $\pm 2^{\circ} \mathrm{F}$.

Durante a aquisição dos dados climáticos foram tomados alguns cuidados. Barbosa (2005) explica que os instrumentos devem ser locados a $1,5 \mathrm{~m}$ do solo considerando em grande parte a altura dos usuários urbanos, além disso, a proteção dos equipamentos da insolação direta e também estarem a uma distância de 1,5 m dos muros e edificações evitando assim a influência de radiação dos materiais urbanísticos.

$\mathrm{Na}$ compreensão da percepção ambiental utilizou-se questionário semi-estruturado com perguntas fechadas previamente elaboradas e aplicados no momento do monitoramento climático, tanto na estação seca quanto na chuvosa, totalizando em 30 questionários, distribuídos 15 para o Ponto 1 e 15 para o Ponto 2. Essa série de perguntas foi organizada com base em BRUN et al. (2010) e ARAÚJO et al. (2010) adaptando aos objetivos do presente estudo.

Após a obtenção dos dados climáticos e da aplicação dos questionários, elaborou-se um banco de dados no programa MS-Excel, por ser um programa que possibilita operar o tratamento estatístico e a representação gráfica.

\section{RESULTADOS E DISCUSSÃO}

\section{Aspecto climático}

A figura 3 apresenta os valores de temperatura e umidade relativa do ar, registrados no período da estação seca, nos dias 14,15 e 16 de Agosto de 2010 para as duas unidades amostrais. De modo que desta, permite inferir que no período da manhã (08h) a diferença entre os pontos monitorados no dia $14 / 08$ foi até $3,1^{\circ} \mathrm{C}$. Esse resultado se assemelha ao estudo de Nogueira et al., (2006) realizado no campus da Universidade Federal de Mato Grosso na cidade de Cuiabá de clima tropical úmido, em que a diferença no período da manhã na estação seca (setembro) chegou a ser de $2,2^{\circ} \mathrm{C}$ entre o ponto com edificação e o ponto com um pequeno bosque. 
Figura 3. Aspectos da temperatura do ar $\left({ }^{\circ} \mathrm{C}\right)$ e da umidade relativa do ar (\%) dos pontos avaliados na estação seca - ponto 1 - com arborização; ponto 2 - área construída

Figure 3. Aspects of air temperature $\left({ }^{\circ} \mathrm{C}\right)$ and relative humidity (\%) of the evaluated points in the dry season - point 1 - with trees; point 2 - built area

08h

20h
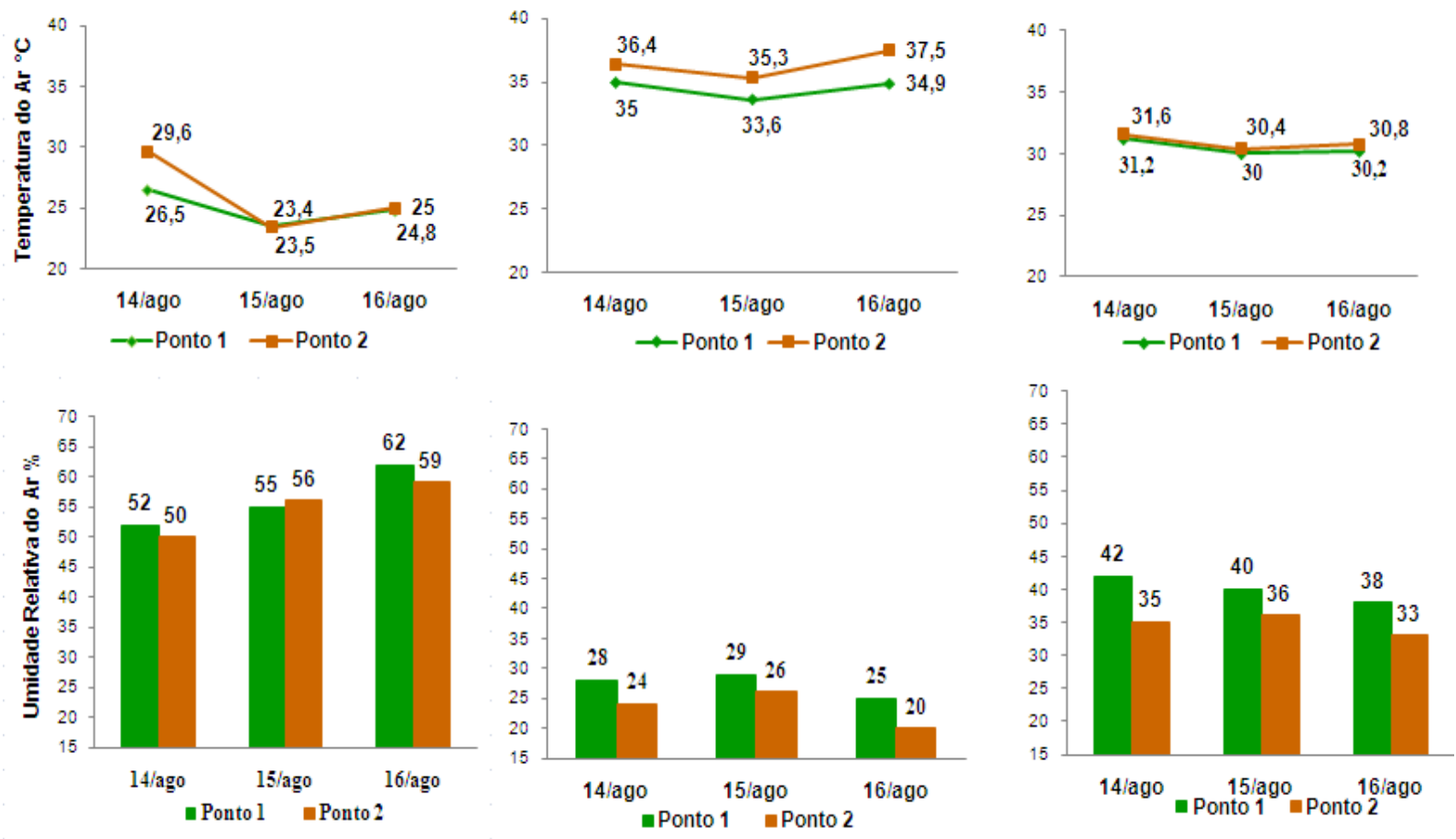

Em relação aos outros dois dias a diferença no período da manhã foi de 0,1 a $0,2^{\circ} \mathrm{C}$, devido à entrada de um sistema frontal que fez atenuar a temperatura do ar nos dias 15 e 16 de Agosto de 2010. Segundo Santos Neto (2010b) a chegada de uma frente fria, durante esse período, ao estado elevou a umidade de $20 \%$ para algo em torno dos $40 \%$ ocasionando também redução nas temperaturas.

Nos períodos de monitoramento vespertinos (14h) o ponto com vegetação apresentou menor aquecimento e a diferença entre os pontos foi na ordem de $1,4^{\circ} \mathrm{C}$ a $2,6^{\circ} \mathrm{C}$. Ao comparar esse dado ao estudo experimental realizado na cidade de Maceió-Al de clima quente e úmido por Barbosa (2010), que constatou também um gradiente térmico de $2,6^{\circ} \mathrm{C}$ entre os pontos com presença e ausência de vegetação. Barbirato et al., (2007, p.112) desenvolveram estudos também na cidade de Maceió-Al e ressaltam que sob os grupamentos arbóreos a temperatura do ar chega a ser de $3^{\circ} \mathrm{C}$ a $4^{\circ} \mathrm{C}$ menor que nas áreas expostas à radiação solar. 
Em relação aos períodos de monitoramento noturnos (20h) há uma tendência de estabilização dos valores da temperatura do ar de apenas $0,6^{\circ} \mathrm{C}$. Essa pequena diferença de temperatura pode ser explicada, como sugere Barbosa (2010), pelo fato que em áreas com presença de vegetação a perda de calor é mais lenta que nos demais ambientes urbanos.

Em relação à umidade relativa (Figura 3), durante o período monitorado, os dados (Figura 3) demonstraram que a maior diferença entre os pontos ocorreu no período da tarde (14h) e da noite (20h) na ordem de $4 \%$ a $7 \%$ respectivamente, sendo ponto 1 a registrar os menores valores. Fato que pode ser explicado pela relação de inversa proporcionalidade existente entre temperatura e umidade e pelo fato que somente com o cair da noite os efeitos de ilhas de calor começam a ser dissipados.

Figura 4. Aspecto da temperatura do $\operatorname{Ar}\left({ }^{\circ} \mathrm{C}\right)$ e da umidade relativa do ar (\%) dos pontos avaliados na estação chuvosa - ponto 1 - com arborização; ponto 2 - área construída

Figure 4. Aspects of air temperature $\left({ }^{\circ} \mathrm{C}\right)$ and relative humidity $(\%)$ of the evaluated points in the rainy season - point 1 - with trees; point 2 - built area
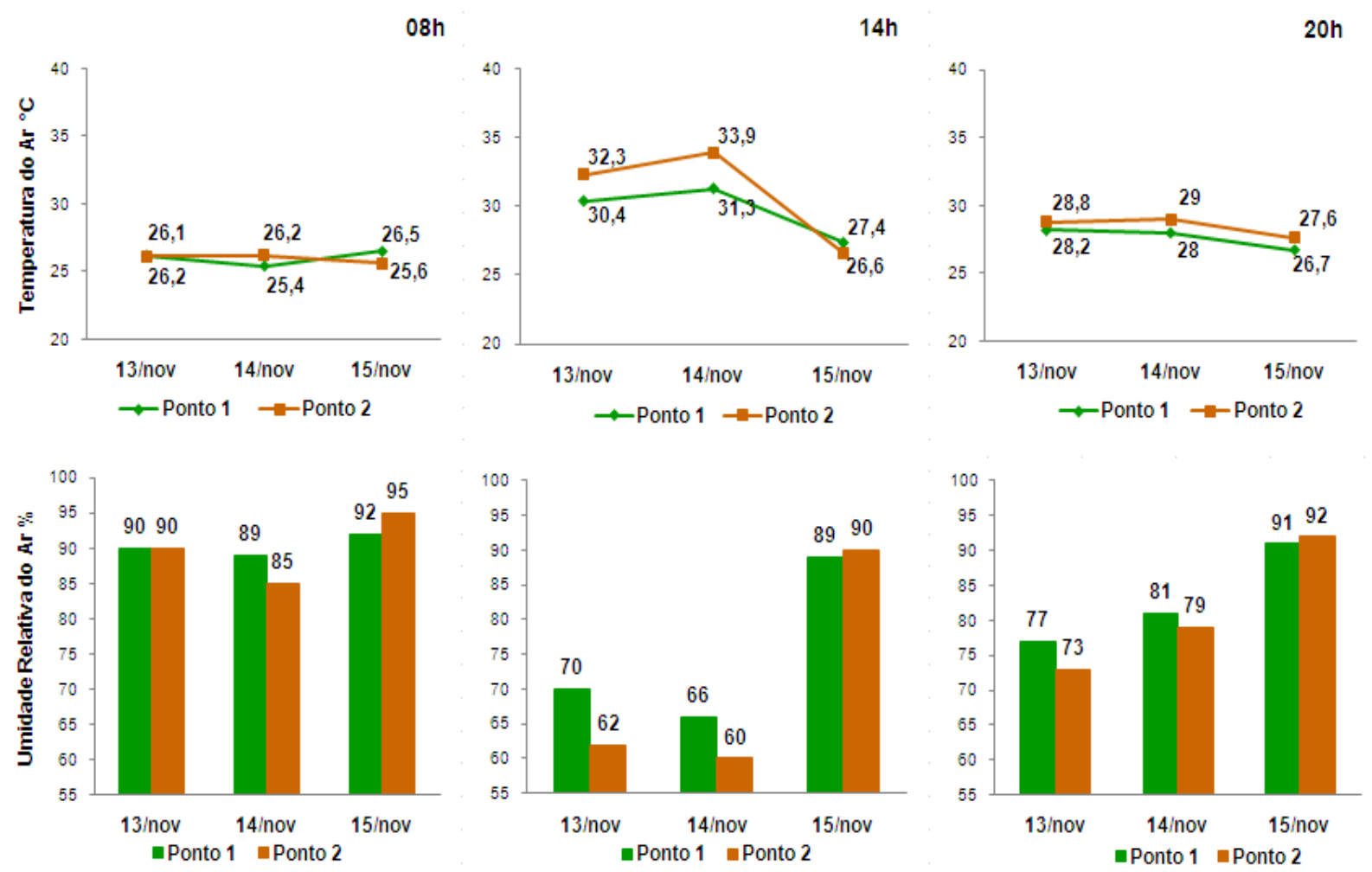
A figura 4 corresponde à análise climática no período da estação chuvosa nos dias 13,14 e 15 de novembro de 2010. Conforme pode ser observado, as maiores diferenças no comportamento higrotérmico entre os pontos experimentais durante o período monitorado na estação chuvosa, ocorreram no turno da tarde (14h), onde o gradiente térmico chegou a atingir $2,6^{\circ} \mathrm{C}$. Nos demais turnos, devido à existência de uma nebulosidade persistente durante turno matutino e a presença de chuvisco também persistente no turno da noite (20 h), não se detectou expressiva diferença climática.

No referente à umidade relativa do ar, durante a estação chuvosa, os dados demostraram que as diferenças mais expressivas ocorreram no turno vespertino, onde as essas atingiram a ordem de $6 \%$ a $8 \%$. Nos demais turnos os valores se mantiveram praticamente equivalentes, com variações em torno de $1 \%$ a $3 \%$.

A comparação dos pontos monitorados entre as estações seca e chuvosa revelou que as diferenças hidrotérmicas são mais destoantes na estação seca. Onde a diferença se deu na ordem de $3,1^{\circ} \mathrm{C}$ a $5^{\circ} \mathrm{C}$ e para a umidade relativa do ar uma amplitude de $20 \%$ entre as estações. A esse respeito Alvarez (2004, p.29 e30) explica que o aumento de energia em áreas urbanas ocorre especialmente durante os dias de verão, pelo fato do grande número de áreas construídas e de ruas que possuem alta retenção de calor e pequeno poder de reflexão e a evapotranspiração é diminuída na área vegetada.

Comparando os dados obtidos nos pontos monitorados com os da estação fixa ${ }^{4}$ e com a Normal Climatológica (Tabela 1), constatou-se que os valores obtidos na estação móvel são sempre superiores aos da estação fixa e as médias da Normal Climatológica. Sendo o ponto 2 a apresentar os valores mais discrepantes, principalmente em relação a menor temperatura, cuja a diferença foi de $6,4 \stackrel{\circ}{ } \mathrm{C}$ (em comparação a mínima registrada pela estação fixa) e de 4,4ํㅡ (em relação a normal climatológica), e a menor umidade relativa do ar, que apresentou $4 \%$ em relação a menor umidade registrada pela estação fixa.

\footnotetext{
${ }^{4}$ Estação Meteorológica código ICAO (Organização da Aviação Civil Internacional) 82824-SBPV, localizada no Aeroporto Internacional Governador Jorge Teixeira, em Porto Velho, RO, Brasil, cuja localização geográfica de $08^{\circ} 46^{\prime} S$ de latitude e $063^{\circ}$ 54 'W de longitude.
} 
Tabela 1. Dados climáticos do período seco da estação fixa e da normal climatológica

Table 1. Dry period climatic data from the fixed station and normal weather

\begin{tabular}{c|c|c|c|c|c|c}
\hline \multirow{2}{*}{ Estação Seca } & \multicolumn{3}{|c|}{ Temperatura do Ar $\left({ }^{\circ} \mathrm{C}\right)$} & \multicolumn{3}{c}{ Umidade Relativa do Ar (\%) } \\
\cline { 2 - 7 } & máx & méd & mín & máx & méd & mín \\
\hline $\mathbf{1 4 / 0 8 / 2 0 1 0}$ & $36^{\circ} \mathrm{C}$ & $29^{\circ} \mathrm{C}$ & $23^{\circ} \mathrm{C}$ & $69 \%$ & $47 \%$ & $22 \%$ \\
\hline $\mathbf{1 5 / 0 8 / 2 0 1 0}$ & $34^{\circ} \mathrm{C}$ & $27^{\circ} \mathrm{C}$ & $21^{\circ} \mathrm{C}$ & $78 \%$ & $51 \%$ & $24 \%$ \\
\hline $\mathbf{1 6 / 0 8 / 2 0 1 0}$ & $34^{\circ} \mathrm{C}$ & $26^{\circ} \mathrm{C}$ & $17^{\circ} \mathrm{C}$ & $94 \%$ & $58 \%$ & $23 \%$ \\
\hline Normal Climatológica & $33^{\circ} \mathrm{C}$ & $25^{\circ} \mathrm{C}$ & $19^{\circ} \mathrm{C}$ & ---- & $82 \%$ & ----- \\
\hline
\end{tabular}

Já ao comparar os dados higrotérmicos obtidos durante o monitoramento realizado na estação chuvosa com os valores obtidos pela estação fixa e com a normal climatológica (Tabela 2), verificou-se que os valores de temperatura e umidade relativa do ar apresentaram comportamento semelhante aos da estação seca. De modo, que as maiores diferenças também foram observadas no ponto 2 , sendo que as maiores diferenças foram em relação a: a temperatura máxima (superior em $3,9^{\circ} \mathrm{C}$ em relação a estação fixa e $2,2^{\circ} \mathrm{C}$ em relação a normal climatológica) e a umidade mínima registrada (inferior a $2 \%$ em relação a menor umidade registrada pela estação fixa).

Assim, observa-se um incremento da temperatura e redução da umidade relativa do ar. Esse efeito foi semelhante ao estudo da caracterização climática de Rondônia proposto pelos autores Zuffo e Franca (2010), no qual ressaltam que pode estar relacionado à intensificação do fenômeno ilha de calor, em decorrência da supressão de áreas verdes e do crescimento urbano.

Tabela 2. Dados climáticos do período úmido da estação fixa e da normal climatológica Table 2. Rainy period climatic data from the fixed station and normal weather

\begin{tabular}{c|c|c|c|c|c|c}
\hline \multirow{2}{*}{ Estação Chuvosa } & \multicolumn{3}{|c|}{ Temperatura do Ar $\left({ }^{\circ} \mathrm{C}\right)$} & \multicolumn{3}{c}{ Umidade Relativa do Ar (\%) } \\
\cline { 2 - 6 } & máx & méd & mín & máx & méd & mín \\
\hline $\mathbf{1 3 / 1 1 / 2 0 1 0}$ & $30^{\circ} \mathrm{C}$ & $27^{\circ} \mathrm{C}$ & $23^{\circ} \mathrm{C}$ & $100 \%$ & $89 \%$ & $62 \%$ \\
\hline $\mathbf{1 4 / 1 1 / 2 0 1 0}$ & $31^{\circ} \mathrm{C}$ & $27^{\circ} \mathrm{C}$ & $23^{\circ} \mathrm{C}$ & $100 \%$ & $87 \%$ & $62 \%$ \\
\hline $\mathbf{1 5 / 1 1 / 2 0 1 0}$ & $30^{\circ} \mathrm{C}$ & $27^{\circ} \mathrm{C}$ & $23^{\circ} \mathrm{C}$ & $100 \%$ & $94 \%$ & $70 \%$ \\
\hline Normal Climatológica & $31^{\circ} \mathrm{C}$ & $26^{\circ} \mathrm{C}$ & $22^{\circ} \mathrm{C}$ & ---- & $87 \%$ & ---- \\
\hline
\end{tabular}




\section{Percepção dos entrevistados sobre o conforto ambiental}

A Figura 5 demonstra a frequência de uso dos pontos avaliados pelos entrevistados. No ponto com vegetação (40\%) raramente frequentam o local e no ponto de área construída (73\%) sempre frequentam o local.

Figura 5. Grau de frequência de uso dos pontos pelos entrevistados: ponto 1 - com arborização; ponto 2 - área construída

Figure 5. Degree of frequency of use by respondents of the points: point 1 - with trees; point 2 - built area
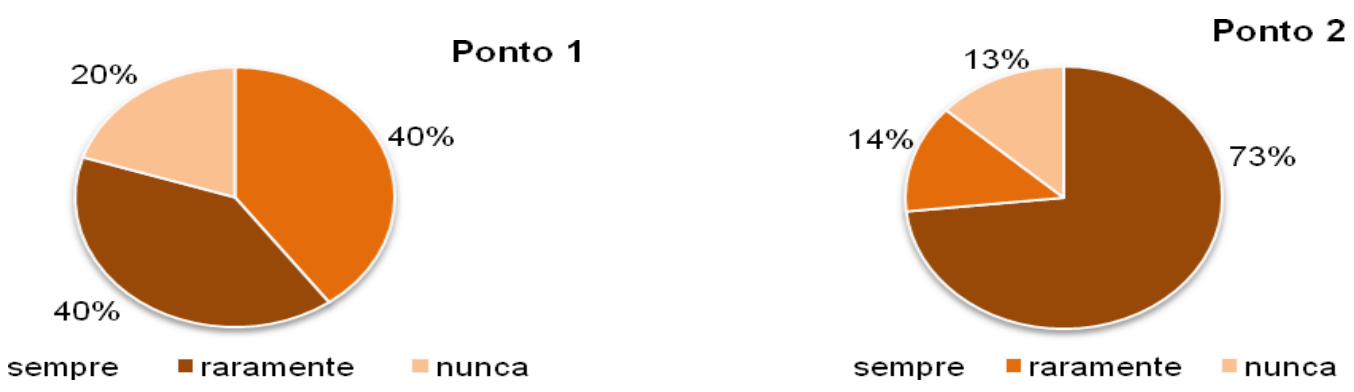

Já a Figura 6 ilustra o motivo pelo qual o entrevistado utiliza o local, no ponto com vegetação (53\%) estão a passeio e no ponto de área construída (67\%) utilizam o local como percurso do trabalho.

Figura 6. Principais motivos alegados pelos usuários em freqüentar os locais avaliados no presente estudo: ponto 1 - com arborização; ponto 2 - área construída

Figure 6. Main reasons given by users in the attend sites assessed in this study: point $1-$ with trees; point 2 - built area

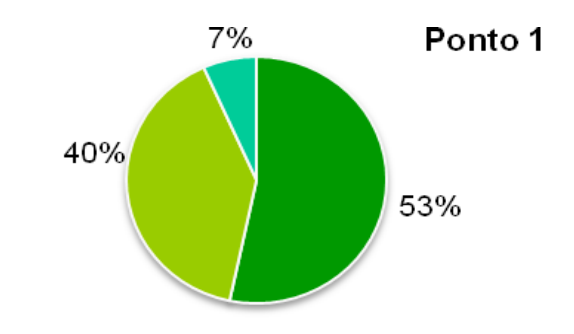

passeio $=$ percurso do trabalho $=$ morador

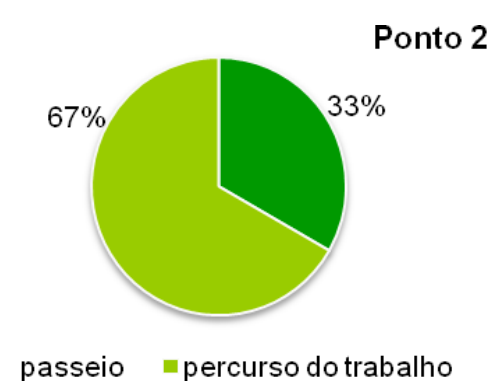


Outro ponto a ser destacado são as vantagens da arborização urbana, assim mais de $50 \%$ indicaram como principal vantagem à redução do calor, no ponto com vegetação. 0 mesmo fator foi indicado no ponto 2 (93\%), embora, apresente ausência de vegetação, concluiu-se a percepção dos entrevistados no proveito de árvores para o meio urbano (Figura 7).

Figura 7. Vantagens da arborização urbana indicados pelos entrevistados nos locais avaliados no presente estudo: ponto 1 - com arborização; ponto 2 - área construída

Figure 7. Benefits of urban forestry indicated by respondents in the areas measured in this study: point 1 - with trees; point 2 - built area

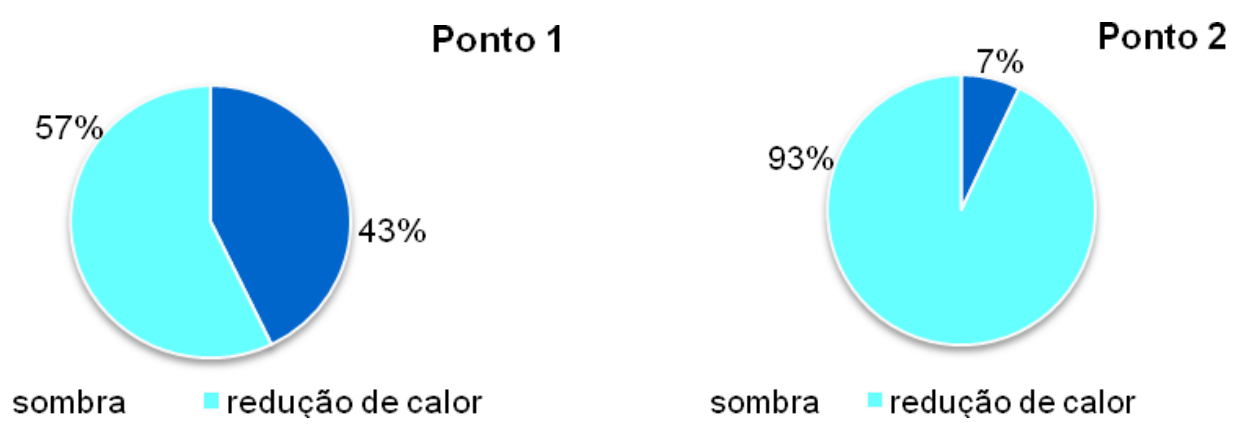

As vantagens da arborização urbana também foi percebido pelos entrevistados na pesquisa realizada por Araújo et al. (2010), em Campina Grande (PB), embora, o fator sombra foi o mais indicado com $60 \%$ seguido do fator redução de calor em $24 \%$. Esse efeito sentido pelos entrevistados é explicado por Alvarez (2004, p.39) em que a cobertura vegetal por meio de suas folhas possui grande influência climática, pois absorve de $15 \%$ a $35 \%$ da energia luminosa recebida durante as horas de insolação, o que resulta em um resfriamento do ambiente de forma direta através do sombreamento.

Quanto aos elementos da paisagem elencados pelos entrevistados nos respectivos pontos, (87\%) indicaram a vegetação como elemento percebido no local arborizado, e no ponto de área construída são os edifícios 53\% o que mais chamam a atenção (Figura 8). Assim verifica-se a importância da vegetação nas vias urbanas no referente ao conforto térmico, posto o valor estimado à vegetação na área arborizada e dos edifícios na área construída. 
Figura 8. Elementos da paisagem indicados pelos entrevistados nos locais avaliados: Ponto 1 - com arborização; ponto 2 - área construída

Figure 8. Landscape elements indicated by respondents in the areas measured: point 1 with trees; point 2 - built area

\section{Ponto 1}

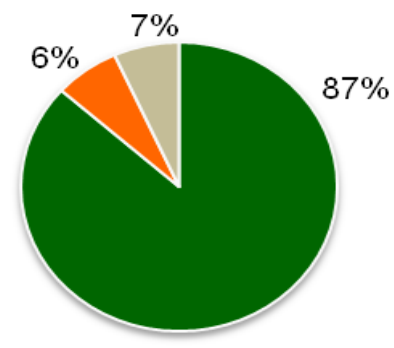

vegetação

casas

nenhuma das alternativas
Ponto 2

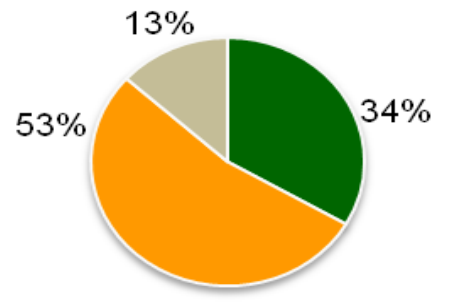

vegetação

edifício

nenhuma das alternativas

Levando em consideração os aspectos estéticos e com base na pergunta anterior foi questionado aos entrevistados quais seriam as melhores condições indicadas para o local. O resultado demonstrou que os entrevistados no ponto1 e 2 respectivamente, propuseram mais vegetação para o local (40\% e $73 \%$ ), mais espaço para circular (33\% e $20 \%$ ) e mais sombra (27\% e 7\%) (Figura 9). Portanto pode-se inferir a necessidade do citadino no tocante a presença de vegetação urbana, ao mesmo tempo que, a introdução de áreas verdes devem ser planejadas, pois $33 \%$ dos entrevistados no ponto 1 , sentem dificuldades de circulação na calçada, principalmente nos locais onde se desenvolve a espécie Oiti (Licania tomentosa) que não são adequadas para a arborização de vias, e sim para praças e parques, conforme estabelece (MARTO, 2006).

Figura 9. Melhores condições indicadas pelos entrevistados nos locais avaliados: ponto 1 com arborização; ponto 2 - área construída

Figure 9. Best conditions given by respondents in the areas measured: point 1 - with trees; point 2 - built area
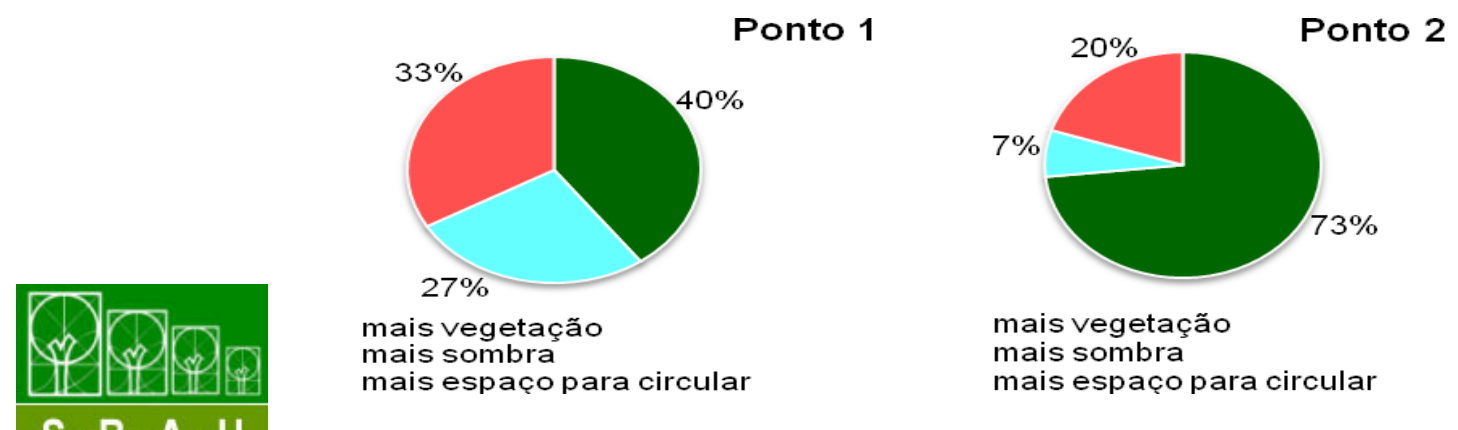

$\mathbf{S} \cdot \mathbf{B} \cdot \mathbf{A} \cdot \mathbf{U}$ Soc. Bras. de Arborização Urbana

REVSBAU, Piracicaba - SP, v.6, n.4, p. 15-34, 2011 
Já na avaliação do conforto climático verificou-se a sensação térmica no momento da entrevista, no qual os interrogados mostraram-se confortável no ponto com vegetação (73\%) e no ponto de área construída (73\%) sentiam-se com muito calor (Figura 10), isso se deve as feições urbanísticas das unidades amostrais.

Figura 10. Avaliação do conforto térmico do local pelos entrevistados: ponto 1 - com arborização; ponto 2 - área construída

Figure 10. Evaluation of thermal comfort of the place by respondents: point 1 - with trees; point 2 - built area
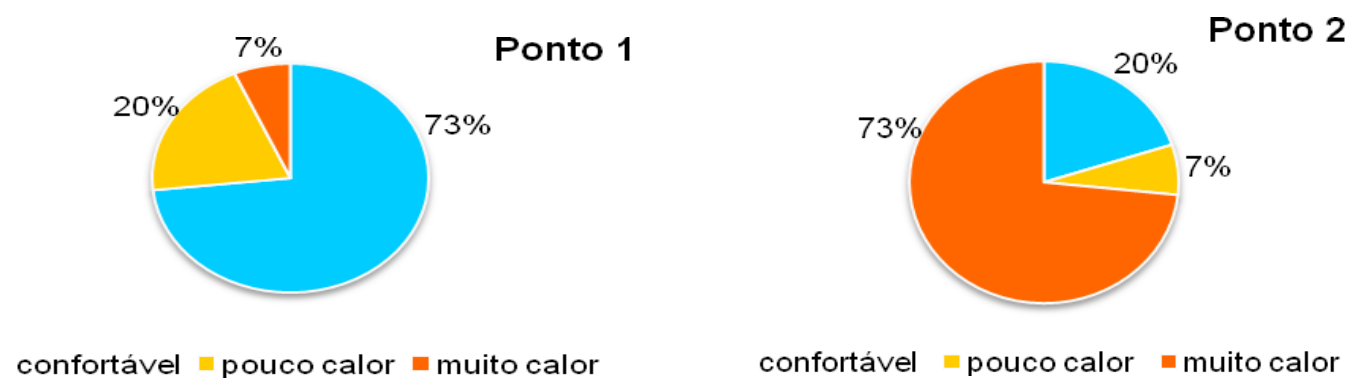

\section{CONCLUSÕES}

As variáveis climáticas analisadas nas áreas estudadas revelaram que a temperatura do ar no ponto com presença de vegetação foi menor em até $5^{\circ} \mathrm{C}$, em relação ao ponto com ausência de vegetação e a umidade relativa do ar apresentou uma diferença de $3 \%$ a $6 \%$ entre um ponto e outro.

Assim, a amplitude térmica observada nas unidades amostrais foi mais significativa na estação seca, período que se configura com baixos índices pluviométricos, sendo que o arranjo amostral onde existe vegetação propiciou ao citadino um conforto térmico.

Quanto à avaliação da percepção ambiental foi possível identificar pelos entrevistados, que a arborização urbana favoreceu vantagens na redução do calor e recomendariam mais áreas verdes propiciando o conforto térmico na urbe.

Portanto, o monitoramento nas unidades amostrais urbanas da cidade de Porto Velho-RO atingiu ao objetivo do presente trabalho comprovando o que a literatura diz a respeito de áreas arborizadas e percepção ambiental. Uma vez, que as áreas verdes cumprem uma função estética, ecológica e social e também propicia em ambientes urbanos 
temperaturas do ar amenas, do que em áreas sem vegetação, garantindo assim uma melhor qualidade de vida ao homem que vive na cidade.

\section{AGRADECIMENTOS}

Os autores agradecem ao Professor de Geografia Reginaldo Martins da Silva de Souza do Instituto Federal de Rondônia (IFRO) pela sua colaboração no trabalho, e a CAPES pelo incentivo ao desenvolvimento deste trabalho através de uma bolsa de Mestrado.

\section{REFERÊNCIAS BIBLIOGRÁFICAS}

ALVAREZ, I. A.. Qualidade do Espaço Verde Urbano: Uma proposta de índice de avaliação. Piracicaba, 2004. 187 f. Tese (Doutorado) Escola Superior de Agricultura Luiz de Queiroz.

ARAÚJO, J. L. O.; ARAÚJO, A.C.; ARAÚJO, A.C. Percepção ambiental dos residentes do bairro Presidente Médici em Campina Grande -PB, no tocante à arborização local. Revista da Sociedade Brasileira de Arborização Urbana. Piracicaba - SP, v.5, n.2, p.67-81, 2010. Disponível em: < http://www.revsbau.esalq.usp.br/artigos_cientificos/artigo117publicacao.pdf $>$. Acesso em: 27/11/2010.

BARBIRATO, G.M.; SOUZA, L. C. L.;TORRES,S. C. Clima e Cidade:A abordagem climática como subsidio para estudos urbanos. Edufal - Editora da Universidade Federal de Alagoas, Maceió. 2007.

BARBOSA, R. V. R. Áreas verdes e qualidade térmica em ambientes urbanos: Estudo em Microclimas de Maceió (AL). São Carlos, 2005. Dissertação (MESTRADO). Escola de Engenharia de São Carlos, Universidade de São Paulo.

Áreas verdes e comportamento térmico urbano. Universidade Federal de Alagoas. GATU - Grupo de Estudo da Atmosfera Climática Urbana. In:Congresso 
Brasileiro de Meteorologia, 2010. Anais... Disponível em: < http://www.cbmet2010.com/anais/artigos/455_61660.pdf > Acesso em: 20/01/2011.

BASTOS, T. X.; SÁ DINIZ, T. D. A. Avaliação do clima do estado de Rondônia para desenvolvimento agrícola. Belém/PA, EMBRAPA-CPATU. Boletim de Pesquisa n44, outubro de 1982.

BIAS, E. S.; BAPTISTA, G. M. M.; LOMBARDO, M. A. Análise do Fenômeno de llhas de Calor Urbanas, por meio da Combinação de Dados LANDSAT e IKONOS. In: XI SBSR. Anais... Belo Horizonte, Brasil, INPE, pp. 1741-1748, 2003.

BRANDÃO, A. M. P. M. 2003. O Clima Urbano da Cidade do Rio de Janeiro. In: MENDONÇA, F.; MONTEIRO, C. A. F. (Eds.). Clima Urbano. Contexto, São Paulo. 192p.

BRASIL. MINISTÉRIO DA AGRICULTURA E REFORMA AGRÁRIA. SECRETARIA NACIONAL DE IRRIGAÇÃO. DEPARTAMENTO NACIONAL DE METEOROLOGIA. Normais Climatológicas (1961-1990). Brasília: [s.n], 1992.

BRUN, F. G. K.; DOBBERT, D. Y.; FILHO,H. J. S.; ZAIA, H. B. A.; FILHO, D. F. S. Percepção dos usuários em relação ao conforto ambiental de duas áreas verdes de Piracicaba - SP. Revista da Sociedade Brasileira de Arborização Urbana. Piracicaba SP, v.5, n.3, p.59-81, 2010. Disponível em: <http://www.revsbau.esalq.usp.br/artigos_cientificos/artigo78-publicacao.pdf >. Acesso em: 27/11/2010.

GAMA, J. M. Clima. In: Atlas Geoambiental de Rondônia. Porto Velho: Secretaria de Estado do Desenvolvimento Ambiental - SEDAM, 2002. Fernandes, L. C.; Guimarães, S. C. P. (org.).

GOMES, M. A. S.; AMORIM, M. C. C. T. Arborização e Conforto Térmico no Espaço Urbano: estudo de caso nas praças públicas de Presidente Prudente (SP). Caminhos de Geografia, Uberlândia, v.7, n.10, p.94-106, set. 2003. Disponível em:

<http://www.seer.ufu.br/index.php/caminhosdegeografia/article/viewFile/10133/6002 >. Acesso em: 09 de Ago 2011. 
GOMES, M. A. S., SOARES, B. R. A Vegetação nos Centros Urbanos: considerações sobre os espaços verdes em cidades médias brasileiras. Estudos Geográficos, Rio Claro - v. 1, n. 1, p. 19-29, 2003.

LOMBARDO, A. M. Ilha de Calor nas Metrópoles o exemplo de São Paulo. Editora Hucitec. São Paulo, 1985.

MARTO, G. B. T.. Arborização Urbana. Instituto de Pesquisas e Estudos Florestais, 2006. Disponível em: <http://www.ipef.br/silvicultura/arborizacaourbana.asp >. Acesso em: $25 / 11 / 2006$.

MENDONÇA, F.; MONTEIRO, C. A. F. (org.); DANNI-OLIVEIRA, I. M.; BRANDÃO, A. M. P. M.; GONÇALVES, N. M. S. (colaboradores). Clima Urbano. Editora Contexto, São Paulo, 2003.

MUNFORD, Lewis. A cidade na historia: suas origens, transformações e perspectivas. São Paulo: Martins Fontes, 2004.

NÓBREGA, R. S.. VITAL, L. A. B. Influência da Urbanização sobre o Microclima de Recife e Formação de Ilha de Calor. Revista Brasileira de Geografia Física. v.03, p.151-156, 2010.

NOGUEIRA, M. C. J. A.; XAVIER, A. L.; NOGUEIRA, J. S.; NETO CAMPOS, A. A.; DE MUSIS, C. R.; OLIVEIRA, A. G. Estudo da influência de diversos tipos de morfologia urbana no microclima do campus da Universidade Federal de Mato Grosso. Uniciências, Vol. 10, No 1 (2006). Disponível em: <http://jano.nide.com.br/index.php/uniciencias/article/view/14 > Acesso em: 24/01/2011 às 14h30min.

PEREIRA, R. V.; FERREIRA, M. F. M. Áreas Verdes e Percepção Ambiental na cidade de Campos Gerais (MG). In: XIII Simpósio Brasileiro de Geografia Física Aplicada: A geografia física aplicada e as dinâmicas de apropriação da natureza. Anais... De 06 a 10 de Julho de 2009, Universidade Federal de Viçosa. Disponível em:

<http://www.geo.ufv.br/simposio/simposio/trabalhos/trabalhos_completos/eixo1/068.pdf>. 


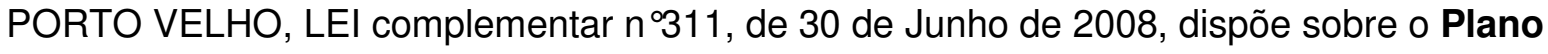
Diretor do Município de Porto Velho. Diário Oficial [do município de Porto Velho], Porto Velho, 2008. Disponível em <http://www.mp.ro.gov.br/web/caoma/porto-velho > Acesso em Nov de 2010.

SANTOS NETO, L. A. Curso de meteorologia para jornalistas. Edição Digital (DIVMETSIPAM-CTO RO), Abr de 2010a. 1 CD-ROM.

Previsão indica alívio na umidade do ar nos próximos dias em $\mathrm{RO}$.

Notícias SIPAM, Porto Velho, p.1-1, 13 ago. 2010b. Disponível em: < http://www.sipam.gov.br/content/view/2933/10/ >. Acesso em: 13/08/2010.

SANTOS, M. Metamorfoses do Espaço Habitado: Fundamentos Teóricos e Metodológicos da Geografia. Denise Elias (colaboração). 6ª Edição. São Paulo: Editora da Universidade de São Paulo, 2008.

SILVA, R. B.; VINHA, E. Vegetação: Biodiversidade de Espécies Florestais. In: Atlas Geoambiental de Rondônia. Porto Velho: Secretaria de Estado do Desenvolvimento Ambiental - SEDAM, 2002. Fernandes, L. C.; Guimarães, S. C. P. (org.).

ZUFFO, C. E; FRANCA, R. R. Caracterização Climática de Rondônia e Variabilidade do Clima em Porto Velho. In: IX Simpósio Brasileiro de Climatologia Geográfica - Climatologia e Gestão do Território. Anais... Fortaleza - Ceará, 26 a 30 de setembro de 2010. 